\title{
Sexual Education for Senior Age: Continuous Increase Inreported Cases of HIV in Brazil - 2005/2015
}

\author{
Dennis Minoru Fujita*, Luiz Henrique da Silva Nali, Paulo Roberto Palma Urbano and Expedito José de \\ Albuquerque Luna
}

Instituto de Medicina Tropical de São Paulo, USP Lab, Brazil

Received: January 29, 2018; Published: February 21, 2018

*Corresponding author: Dennis Minoru Fujita, Av Dr Enéas Carvalho de Aguiar, 470 - 2º andar, São Paulo - Brazil, Tel: 551130613684; Email: dmfujita@usp.br

\section{Introduction}

The economic development in emerging countries promoted an increase of access for new medical technologies and services which improve the life expectancy of your population at last 10 years [1]. In Brazil, the increase of senior group is accompanied by new demands for a better quality of life, based on the interaction and social integration of the elderly [2]. However, this social renaissance may be followed by agents that did not represent a risk for this group [3]. Either by lack of preventive knowledge or by the cultural conduct to not use condoms, in the past, of this generation. Our study assessed the number of HIV-infected from Brazilian Ministry of Health public database (DATASUS) during the last 10 years. We focused on analyzing the frequency in senior age group, which was divided in the following distribution by age: 60-64, 65-69, 70-74, 75-79 and 80<years old. We compared the price's evolution from the two main drugs for erectile dysfunction (Drug 1 and Drug 2) at Agência Nacional de VigilânciaSanitária - ANVISA database in the last 10 years. Today, there are $\sim 36.7$ million people infected by HIV in the world, whereas in Brazil there was an increase in estimated number of people (all ages) living with HIV(n 700.000 in 2010/ $\mathrm{n} \sim 830.000$ in 2015) in Brazil, with an estimative of $\sim 15.000$ deaths/year [4].

In Brazil, the group from 60 to 64 years old (Table 1A) initially presented a considerable number of HIV reported cases $(n=5069$ - 2005) by different transmission routes of infection including sex and still concern after 10 years in this specific age group $(n=7797$ - 2015) with an increase of 53.82\%. The last age group ( $80<$ years) presents a considerable estimated prevalence of HIV $(n=2.112$ in $2005 / n=3.308$ in 2015 ) presenting an increase of $56.63 \%$. This result might be explained by multiple reasons as follows: The drugs for erectile dysfunction presented more options of dosage with the reduction of the active ingredient (Drug 1 - $25 \mathrm{mg}, 50 \mathrm{mg}$ and $100 \mathrm{mg} /$ Drug 2 - $20 \mathrm{mg}$ ) and consequent price reduction, (Drug 1 - R\$24.210 - 25mg - 1pill / Drug 2- R \$52.49- 20 mg -1pill) which provide more presence and availability to a larger group of consumers in Brazil according to ANVISA's database in 2016 (Table 1B). The increase in Brazilian life expectancy present a continuous growth that was $9.8 \%$ in 2005 and in 2015, the last available data, was $14.3 \%$ shows us new problems related to the resocialization in old age, which includes the right to leisure, group activities and even sexual activity.

Considering the diversity of drugs for erectile dysfunction available in the market and their relative decrease in price over the last 10 years in Brazil, allied to the growing participation of old group in dating apps (56 to 64 year olds - doubled the use of online dating services from 2013 to 2015) (Table 1C) [5]. The estimative of individuals living with HIV in all old age group in Brazil (60 to 80 years old - $n=23.940 \mathrm{in} 2015$ ), and the constant increase of reports at last 10 years $(>86.17 \%)$, may be consider as a consequence from a unexpected problem (Figure 1). Probably, the monogamous behavior induced by social and religious precepts protected this population at past, but in the search for a new companion, they may develop unprotect sex because contraception was the big problem at their young age, and disregard the dangers of sexually transmitted diseases, since they were a problem related only to people with "questionable character", as drug addicts [6]. Emerging countries have similar growth of their elderly population and may present the same problems with considerable development of sexually transmitted diseases in the senior age. We may consider urgent a sexual education program for this special age group, and maybe a more specific palliative method in the sale of these drugs to this group, due to this continuous increase in HIV prevalence in old age.

Table 1A: Estimated Prevalence of HIV in Elder People-Brazil.

\begin{tabular}{|c|c|c|c|c|c|c|}
\hline Year & $\mathbf{6 0 - 6 4}$ & $\mathbf{6 5}-\mathbf{6 9}$ & $\mathbf{7 0 - 7 4}$ & $\mathbf{7 5 - 7 9}$ & $\mathbf{8 0}>$ & Total \\
\hline 2005 & 5.069 & 4.063 & 2.989 & 2.133 & 2.112 & 16.367 \\
\hline
\end{tabular}




\begin{tabular}{|c|c|c|c|c|c|c|}
\hline 2006 & 5.271 & 4.162 & 3.082 & 2.190 & 2.211 & 16.918 \\
\hline 2007 & 5.513 & 4.250 & 3.194 & 2.239 & 2.322 & 17.520 \\
\hline 2008 & 5.783 & 4.343 & 3.314 & 2.287 & 2.440 & 18.170 \\
\hline 2009 & 6.065 & 4.462 & 3.430 & 2.345 & 2.560 & 18.864 \\
\hline 2010 & 6.348 & 4.621 & 3.535 & 2.418 & 2.677 & 19.601 \\
\hline 2011 & 6.633 & 4.817 & 3.631 & 2.504 & 2.795 & 20.382 \\
\hline 2012 & 6.919 & 5.048 & 3.719 & 2.605 & 2.915 & 21.208 \\
\hline 2013 & 7.207 & 5.306 & 3.810 & 2.713 & 3.039 & 22.077 \\
\hline 2014 & 7.499 & 5.575 & 3.925 & 2.818 & 3.169 & 22.988 \\
\hline 2015 & 7.797 & 5.844 & 4.076 & 2.913 & 3.308 & 23.938 \\
\hline Increase (\%) & $>53.82 \%$ & $>43.83 \%$ & $>36.37 \%$ & $>36.57 \%$ & $>56.63 \%$ & $>46.26 \%$ \\
\hline
\end{tabular}

Table 1B: Price Evolution (BRL Currency*) - Erectile Dysfunction Drugs.

\begin{tabular}{|c|c|c|c|c|c|c|c|c|}
\hline & Drug 1 & Drug1 & Drug1 & Drug1 & Drug2 & Drug2 & Drug2 & Drug \\
Year & $\mathbf{2 5 m g}$ & $\mathbf{5 0 ~} \mathbf{~ m g}$ & $\mathbf{5 0 ~} \mathbf{~ m g}$ & $\mathbf{1 0 0 m g}$ & $\mathbf{2 0 m g}$ & $\mathbf{2 0 m g}$ & $\mathbf{2 0 m g}$ & $\mathbf{2 0 m g}$ \\
& $\mathbf{4 P i l l s}$ & $\mathbf{1 P i l l}$ & $\mathbf{4 P i l l s}$ & $\mathbf{4 P i l l s}$ & $\mathbf{1 P i l l}$ & $\mathbf{2 P i l l s}$ & $\mathbf{4 P i l l s}$ & $\mathbf{8}$ Pills \\
\hline 2005 & 106.01 & - & 116.54 & 182.47 & - & 69.92 & 139.83 & 279.68 \\
\hline 2006 & 107.08 & - & 117.72 & 184.29 & - & 70.62 & 141.23 & 282.47 \\
\hline 2007 & 107.08 & - & 117.72 & 184.29 & - & 70.62 & 141.23 & 282.47 \\
\hline 2008 & 116.25 & - & 127.8 & 200.08 & - & 76.67 & 153.34 & 306.67 \\
\hline 2009 & 116.25 & - & 127.8 & 200.08 & - & 76.67 & 153.34 & 306.67 \\
\hline 2010 & 121.43 & - & 133.48 & 208.98 & - & 80.08 & 160.15 & 320.32 \\
\hline 2011 & 62.86 & 17.28 & 138.21 & 108.19 & - & 82.93 & 165.82 & 331.66 \\
\hline $2012 * *$ & 66.54 & 18.29 & 146.29 & 114.52 & - & 87.77 & 175.52 & 351.07 \\
\hline 2013 & 70.75 & 19.44 & 155.53 & 121.75 & 46.66 & 93.32 & 186.59 & 373.22 \\
\hline 2014 & 74.77 & 20.55 & 164.36 & 128.66 & 49.31 & 98.61 & 197.19 & 394.43 \\
\hline 2015 & 78.51 & 21.58 & 129.76 & 101.58 & 46.65 & 93.3 & 186.57 & 373.19 \\
\hline
\end{tabular}

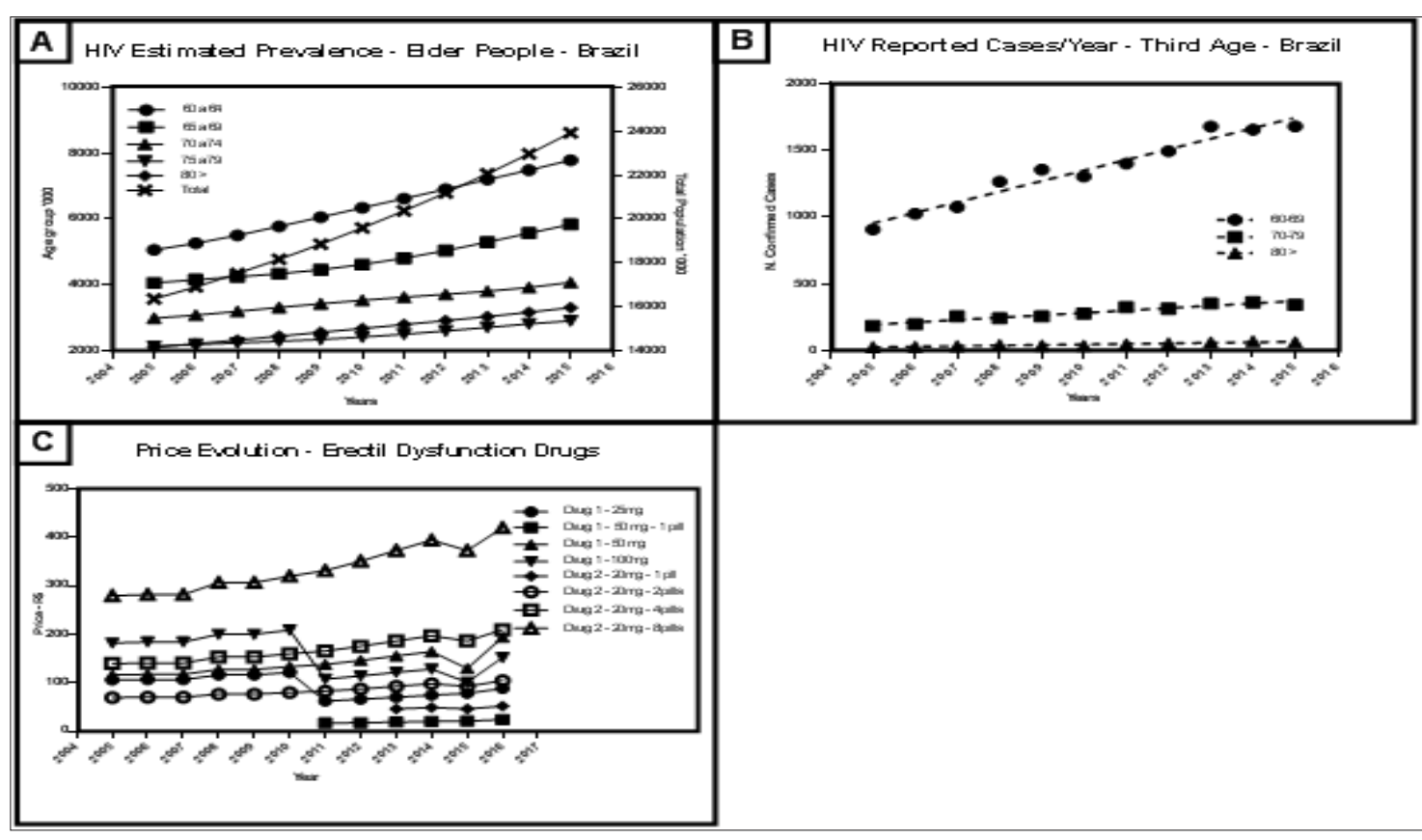

Figure 1: If the overall slopes were identical, there is less than a $0.01 \%$ chance of randomly choosing data points with slopes this different. We can conclude that the differences between the slopes are extremely significant. Because the slopes differ so much, it is not possible to test whether the intercepts differ significantly. 
Table 1C: HIV Positive Cases Reported/Age - Brazil - 2005/2016.

\begin{tabular}{|c|c|c|c|c|c|c|c|c|c|c|c|c|c|c|}
\hline Year & \multicolumn{14}{|c|}{ Age Group } \\
\hline & $<1$ & $1-4$ & $5-9$ & $10-14$ & $15-19$ & $20-29$ & $30-39$ & $40-49$ & 50-59 & $60-69$ & $70-79$ & $80>$ & $\mathrm{NC}^{* * *}$ & Total \\
\hline 2005 & 328 & 487 & 380 & 201 & 547 & 8.298 & 13.581 & 9.303 & 3.598 & 909 & 184 & 28 & 4 & 37.848 \\
\hline 2006 & 303 & 387 & 299 & 190 & 593 & 8.056 & 13.155 & 9.362 & 3.535 & 1.026 & 198 & 29 & 0 & 37.133 \\
\hline 2007 & 288 & 329 & 277 & 221 & 584 & 8.239 & 13.288 & 9.633 & 3.937 & 1.075 & 258 & 34 & 0 & 38.163 \\
\hline 2008 & 279 & 344 & 241 & 236 & 688 & 8.856 & 13.571 & 10.267 & 4.472 & 1.268 & 242 & 43 & 1 & 40.508 \\
\hline 2009 & 265 & 322 & 208 & 202 & 674 & 8.895 & 13.590 & 10.099 & 4.463 & 1.358 & 255 & 37 & 0 & 40.368 \\
\hline 2010 & 268 & 302 & 196 & 172 & 670 & 8.920 & 13.018 & 10.031 & 4.677 & 1.305 & 277 & 36 & 0 & 39.872 \\
\hline 2011 & 281 & 212 & 165 & 178 & 763 & 9.379 & 13.869 & 10.433 & 4.789 & 1.402 & 326 & 48 & 0 & 41.845 \\
\hline 2012 & 222 & 274 & 122 & 157 & 850 & 9.542 & 13.417 & 10.071 & 4.899 & 1.495 & 314 & 54 & 12 & 41.429 \\
\hline 2013 & 199 & 250 & 119 & 133 & 952 & 9.981 & 13.402 & 9.995 & 5.130 & 1.681 & 353 & 60 & 11 & 42.266 \\
\hline 2014 & 212 & 212 & 120 & 117 & 1.000 & 9.807 & 12.867 & 9.468 & 5.109 & 1.657 & 363 & 71 & 4 & 41.007 \\
\hline 2015 & 199 & 182 & 96 & 88 & 951 & 9.546 & 12.165 & 8.771 & 5.028 & 1.683 & 342 & 62 & 0 & 39.113 \\
\hline
\end{tabular}

\section{Acknowledgment}

The authors wish to acknowledge the assistance from Institute de Medicina Tropical de São Paulo - USP, LIM - 49 / LIM - 52 HCFMUSP, FAPESP and CAPES.

\section{References}

1. Mondal MNI, Shitan M (2013) Impact of Socio-Health Factors on Life Expectancy in the Low and Lower Middle Income Countries. Iran J Public Health [Internet]. Tehran University of Medical Sciences 42: 1354-1362.

2. da Fonte E, Feitosa PH, de Oliveira Neto LT, de Araújo CL, Figueiroa JN, et al. (2016) Effects of a physical activity program on the quality of life among elderly people in Brazil. J Fam Med Prim Care 5: 139-142.
3. Fagundes LJ, Vieira EE, Moysés ACMC, Lima FD de, Morais FRB de, et al. (2013) Sexually transmitted diseases in a specialized STD healthcare center: epidemiology and demographic profile from January 1999 to December 2009. An Bras Dermatol 88: 523-529.

4. (2017) World Health Organization. WHO - HIV WHO, World Health Organization.

5. Kevin Murnane (2016) Report Shows More People Of All Ages Are Dating Online.

6. Batista AFO, Marques APO, Leal MCC, Marino JG, Melo JMA (2011) Idosos: Associação entre oconhecimento da aids, atividade sexual e condições sociodemográficas. Rev bras geriatr gerontol 14: 39-48.

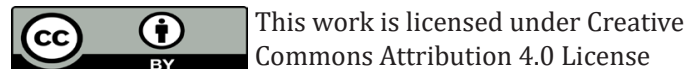

Submission Link: http://biomedres.us/submit-manuscript.php

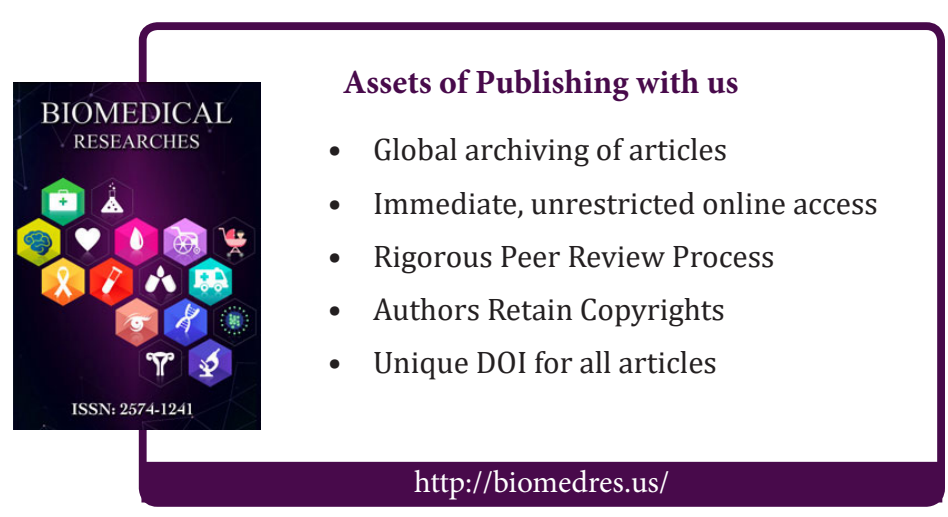

